\title{
Phenolic Compounds with Anti-virulence Properties
}

\author{
Naybi Muñoz-Cazares, Rodolfo García-Contreras, \\ Macrina Pérez-López and Israel Castillo-Juárez
}

Additional information is available at the end of the chapter

http://dx.doi.org/10.5772/66367

\begin{abstract}
Natural products represent the major source of approved drugs and still play an important role in supplying chemical diversity as well as new structures for designing more efficient antimicrobials. They are also the basis for the discovery of new mechanisms of antibacterial action. In this regard, a large number of substances, mainly extracts from natural sources, have been obtained in order to identify their anti-virulence activity. In recent years, there is an increase in the study of anti-virulence natural product derivatives. Different targets have been proposed as a solution to the serious problem of bacterial antibiotic resistance. Inhibition of bacterial quorum-sensing systems has been one of the most studied; however, there are other mechanisms involved in virulence regulation, damage to the host and bacterial survival, which suggests that there are another good targets such as bacterial secretion systems, biofilm formation, two-component systems, flagellum, fimbriae, toxins and key enzymes. Within the natural products, the main anti-virulence compounds are phenolic in nature, so that the next chapter describes and analyzes the relationship between chemical structure and activity of the main phenolic compounds reported.
\end{abstract}

Keywords: anti-virulence, quorum sensing, antibiotic resistance, phytochemicals, antibiofilms

\section{Introduction}

Since their introduction in the middle forties, antibiotics had been extensively used for the treatment of infectious diseases, producing remarkable results and saving millions of lives worldwide [1]; nevertheless, bacteria are very dynamic organisms able to interchange genes by several mechanisms including conjugation, transformation and transfection via 
bacteriophages [1]. In addition, they usually replicate at high rates and hence have the ability to evolve quickly and adapt to strong selective pressures; this combined with the selfprescription, inadequate prescription by some physicians (e.g., to treat viral diseases) and their improper use by patients who do not complete the recommended treatment scheme has derived in an alarming situation since to date antibiotic resistance (including multiresistance and panresistance) is a common trend in most of hospital-acquired infections and is becoming more common in community-acquired ones $[2,3]$. In fact, the situation is so delicate that recently, the OMS warned that if the current trends are still observed, then by the year 2050 we will enter the post-antibiotic era and previously treatable infectious diseases will cause more deaths than other important diseases such as cancer [4].

Hence, the discovery of new antibiotics as well as the development of alternative approaches to combat bacterial infections is urgently needed [5]; among such new approaches are the inhibition of bacterial antibiotic resistance mechanisms, the utilization of non-antibiotic bactericide agents such as bacteriophages, the repurposing of clinically approved drugs, and the inhibition of bacterial virulence [5]. For the first approach, already successful examples can be found in the clinic; by instance, the co-utilization of clavulanic acid (an inhibitor of $\beta$-lactamases) and amoxicillin is commonly administrated [6]; and current research is focused on the utilization of broad spectrum anti-resistance compounds such as those inhibiting multidrug efflux pumps [7]. Regarding the second approach, it was recently demonstrated that some anticancer drugs such as 5-fluorouracil [8], mitomycin C [9] and cisplatin [10] have remarkable antibacterial properties, while bacteriophages had been used in east European countries for the treatment of diverse bacterial infections, and currently, its utilization in the occidental medicine is being proposed [11, 12]. Finally, targeting bacterial virulence instead of their viability is a concept that had derived in several publications, mostly centered in the inhibition of master virulence regulators such as quorum-sensing (QS) systems, which allow several Gram-negative and Gram-positive bacteria to coordinate the production of several virulence factors, once a high population density is reached (Figure 1A). Indeed, initially, it was claimed that this approach will be impervious to the generation of resistance since in vitro in rich media QS does not control metabolic processes linked to growth; nevertheless, in some conditions, QS inhibition can promote resistance [13-15] and not all clinical strains are sensitive toward current QS inhibitors [16]. However, since QS also regulates the stress response, it has been shown that QS-inhibited bacteria are more susceptible to the action of disinfectants, antibiotics and the immune system [17, 18], and hence, QS inhibition may be a valuable adjuvant therapy for recalcitrant bacterial infections [15].

As mentioned previously, QS is a master regulator of the production of several bacterial virulence factors, such as: exoproteases that degrade connective tissue such as elastase and alkaline protease (collagenase), phenazines that promote the generation of reactive oxygen species, siderophores that facilitate iron uptake, toxins that disrupt cellular processes and exopolysaccharides that form phagocytosis-resistant capsules and participate in the generation of the biofilm matrix [19] (Figure 1C).

Another key factor for the development of chronic infections and colonization of surfaces is the formation of biofilms, which is the main way the bacteria are found in nature [20]. 


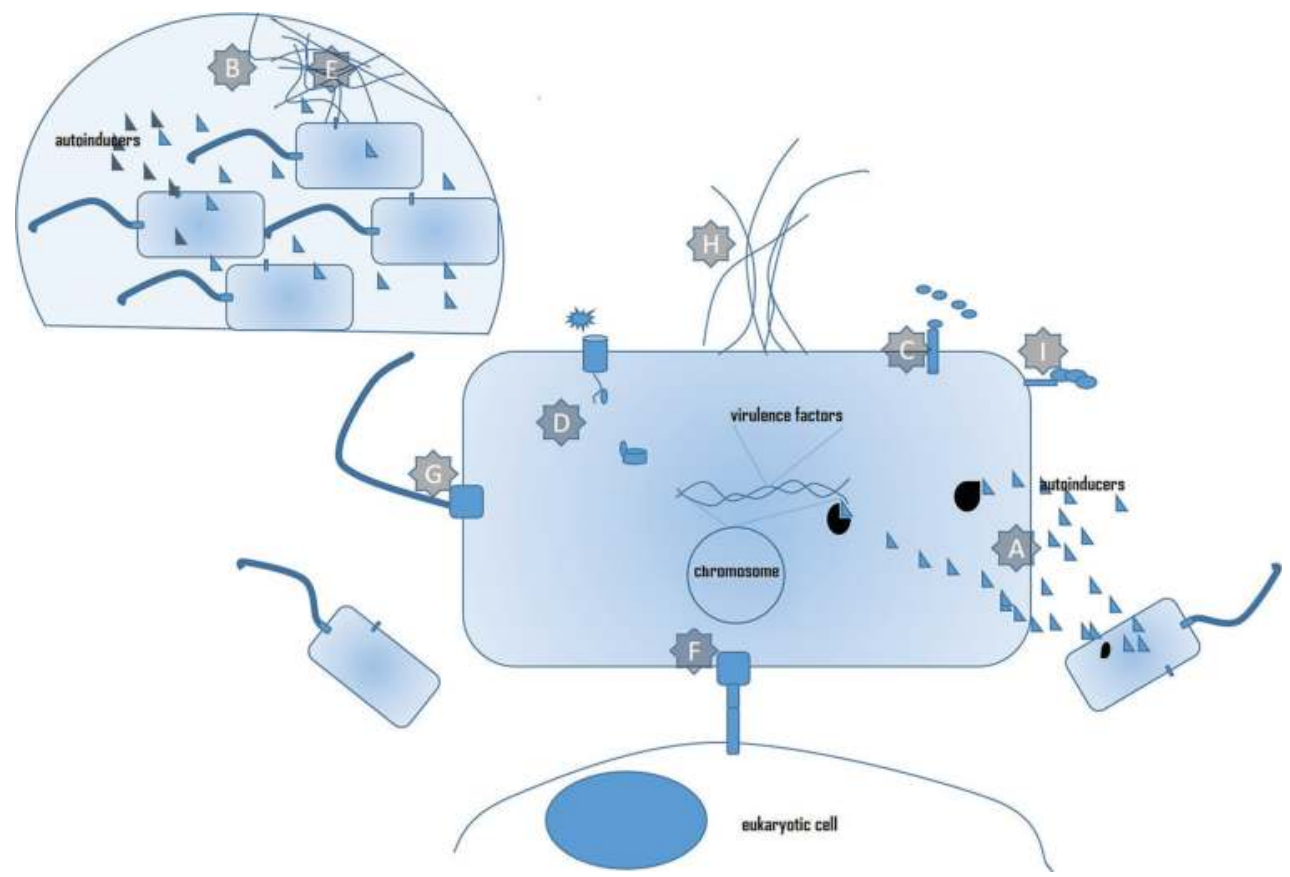

Figure 1. Main targets of anti-virulence of phenolic compounds. A: Quorum-sensing system, B: biofilm formation, C: toxins, D: two-component systems, E: curli fibers, F: bacterial type III secretion systems, G: flagellum, H: fimbriae, I: sortase enzymes.

These structures consist of multicellular communities enclosed in a matrix which makes them extremely resistant to antibacterial agents (Figure 1B) [21]. They also provide robust niches that allow the bacteria to protect themselves from environmental fluctuations and against the immune system, which drastically reduces the effectiveness of antimicrobial therapy [20].

Since for many pathogenic bacteria QS is the main regulator of expression of bacterial virulence factors [19], its disruption has been the main anti-virulence strategy investigated to date [19]. However, another alternative that has also been reported is the direct inhibition of individual virulence factors, such as toxins, response regulators (two-component regulatory systems (TCS) and processes involved in the formation and maturation of structures such as the curli, the bacterial type III secretion system (T3SS), fimbriae and flagellum.

TCS are response regulators which are formed by a protein localized in the cytoplasmic membrane called histidine kinase sensory protein (HKSP), which acts as an environmental sensor that is activated in ATP-dependent way (Figure 1D) [22]. HKSP then activates a response regulator protein (RRP) found in the cytoplasm which is responsible for recognizing DNA sequences that modulate the expression of genes involved in various functions such as chemotaxis, porin expression and expression of virulence factors among others (Figure 1D) [22]. An important feature is that TCRs have not detected in mammalian cells, so there are a suitable specific target to treat bacterial infections [23]. 
The curli (Figure 1E) is the major protein component of the extracellular matrix and is mainly produced by enterobacteria to aid in the formation of three-dimensional structures such as biofilms [24]. Curli fibers belong to a growing class of fibers known as amyloid fibers, which are also involved in host cell adhesion and invasion, and are also strong inducers of host inflammatory response [24]. The structure and biogenesis of curli are unique among bacterial fibers and represent an excellent anti-virulence target [25].

The type III secretion system (T3SS) also known as the injectisome is a multiprotein apparatus that facilitates the secretion and translocation of toxins or effector proteins from the bacterial cytoplasm directly to eukaryotic cells (Figure 1F) [26, 27]. It is highly conserved in most Gram-negative pathogens, but its presence is not a necessary condition for bacterial survival in vitro [27].

Motility and recognition surfaces are key factors for the dispersal and colonization of new niches by bacteria [28]. For that, the flagellum and the fimbriae are target structures suitable for anti-virulence molecules [28, 29]. The flagella (Figure 1G) are multiprotein complexes based on flagellin, which rotate allowing bacterial displacement in aqueous media [29], while fimbriae (Figure $\mathbf{1 H}$ ) are extracellular protein structures mainly constituted by pilin, which start in the plasma membrane, cross the cell wall and extend around the cell. These structures allow the adhesion of bacteria mainly to epithelial cells [30].

Another important virulence factors are the sortase enzymes (cysteine transpeptidases) (Figure 1I), which are used by Gram-positive bacteria to display proteins in cell surface, such as glycoproteins [30], and they can also attach to proteins in the cross-bridge peptide of the cell wall or link other proteins together to form pilin [31]. The phenomenon of protein deployment is essential for the development of virulence factors and promotes nutrient acquisition, adhesion and immune system evasion [30]. Because surface proteins play a fundamental role in microbial physiology and are frequently virulence factors, sortase enzymes are a very important target [31].

Reports related to the study of natural products as anti-virulence molecules had increased in the last decade. Their powerful attack against bacterial infections without promoting resistance and the elimination of antibiotic-resistant strains are the most attractive features of this kind of compounds. Among natural products with anti-virulence activity, those derived from plants with anti-QS and antibiofilm activity are the most common [32]. Phenolic compounds are secondary metabolites present in plants, which are crucial in many aspects of their lives, especially during the interactions with the environment, since they are used in the defense of plants against bacterial pathogens. Similarly, compounds of phenolic type are the major metabolites with anti-virulence properties described so far, and specifically, the flavonoids are the main representatives [33].

Most of the biologically active reported phenolic compounds have chemical structures with previously identified antimicrobial, antioxidant and anticancer activity. Similarly, for some of them their participation in the regulation of various physiological functions in plants and animals is well known. In recent years, the anti-virulence properties of phenolic compounds are being unravel, and most of the cases depend on the compound concentration and the bacterial 
system in which the phenolic compounds can exhibit bactericidal or anti-virulence effects. In the next chapter, we discuss studies of phenolic compounds derived mainly from plant species, starting with those that are better characterized and that have more anti-virulence reported properties. We focus on the relationship between their structures and their activity.

\section{Phenolic compounds anti-virulence}

\subsection{Epigallocatechin gallate and related compounds}

It is well documented that this kind of compounds has antimicrobial, antioxidant, anti-inflammatory, hypocholesterolemic and cancer-preventive properties [34, 35]. The epigallocatechin gallate (EGCG) (Figure 2A) is one of the flavonoids with the largest number of reports related to its antibiofilm activity; remarkably high compound doses can inhibit bacterial growth, but sublethal concentrations exhibit anti-virulence properties.

At the same concentration, catechin (Figure 2B) and EGCG inhibit the formation of biofilms of P. aeruginosa; however, only catechin do not affect the growth [36], so the presence of galloyl<smiles>OC1=C(c2ccc(O)c(O)c2)Oc2cc(O)cc(O)c2C1</smiles>

B<smiles>O=C(OC1=C(c2cc(O)c(O)c(O)c2)Oc2cc(O)cc(O)c2C1)c1cc(O)c(O)c(O)c1</smiles><smiles>COc1cc(C2=C(OC(=O)c3cc(O)c(O)c(O)c3)Cc3c(O)cc(O)cc3O2)ccc1O</smiles><smiles>OC1=C(c2ccc(O)c(O)c2)Oc2cc(O)cc(O)c2C1</smiles>

D<smiles>O=C(OC1=C(c2ccc(O)c(O)c2)Oc2cc(O)cc(O)c2C1)c1cc(O)c(O)c(O)c1</smiles>

Figure 2. Epigallocatechin gallate and related compounds with anti-virulence properties. A: Epigallocatechin gallate, B: catechin, C: catechin-gallate, D: catechin-gallate, E: (-) epicatechin gallate. 
group in EGCG seems to favor the bactericidal effect. In this regard, it is suggested that EGCG affect the viability because it binds to peptidoglycan, hence directly disrupting the integrity of the bacterial cell wall. Similarly, EGCG at concentrations that affect bacterial viability inhibit the biofilm of Enterococcus faecalis, an opportunistic pathogen implicated in urinary tract infections, endocarditis and root canal infections [37]. In this case, biofilm inhibition is attributed to a bactericidal effect, where the EGCG induces hydroxyl radicals that can damage DNA, proteins and lipids [37].

However, using sublethal concentrations, it has been found that EGCG significantly decreased the expression of virulence genes that regulate the expression of cytolysins, gelatinase and serine protease in E. faecalis [37]. It also inhibits biofilm formation of Staphylococcal isolates by interfering directly with polysaccharides of the glycocalyx [38]. Similarly, it inhibits swarming and biofilm formation of Burkholderia cepacia without affecting the growth, likely through QS inhibition [39].

EGCG and catechin gallate (Figure 2C) directly inhibit the anthrax lethal factor (LF) produced by Bacillus anthracis, which has a key role in the development of anthrax [40]. LF is a zinc metalloprotease that directly affects MAPK-signaling kinases, which are essential for transmitting signals in eukaryotes. EGCG and catechin gallate block the activity of LF, preventing MAPK-kinases cleavage and macrophages death [40]. In the case of EGCG, it also delays the death of mice exposed to the anthrax toxin [40]. It is noteworthy that although other catechins were evaluated, the presence of a galloyl group in the structure seems to be essential for this anti-virulence activity.

For the case of catechin (Figure 2B), it has also been reported that it inhibits the production of virulence factors regulated by QS in P. aeruginosa, such as pyocyanin and elastase [41]. Also, it was found to have a negative impact on the transcription of several genes involved in QS, such as those codifying proteins involved in the synthesis of autoinducer molecules [41].

Dental plaque is a complex biofilm that allows the survival and development of Streptococcus mutans. It has been reported that EGCG shows bactericidal activity against S. mutans; in addition, its antibiofilm activity is due to reducing the adherence of bacteria to surfaces by direct inhibition of glucosyltransferases [42], which are enzymes that synthesize polysaccharides $[43,44]$. However, at sublethal concentrations, EGCG reduces biofilm by interfering with gene regulation, specifically by inhibiting the expression of the gtf genes (encoding glucosyltransferases), which are associated with adhesion and formation of biofilms [45]. Moreover, it represses genes encoding virulence factors associated with acidogenicity and acidurity, such as $l d h$, eno, dATP, Agud and the activity of the $\mathrm{F}_{1} \mathrm{~F}_{0}$-ATPase and lactate dehydrogenase [42].

EGCG at sublethal concentrations also inhibits motility and biofilm formation of Campylobacter jejuni, a foodborne pathogen which is one of the main causes of gastrointestinal infections worldwide [46]. In this case, the mechanism involved in biofilm inhibition is related to QS inhibition [46].

It is worth noting that to date there are no studies to investigate its structure-activity relationship, so it is not yet known which parts of the structure are critical to their anti-virulence effects. However, for the (-) epicatechin (Figure 2D) which also possesses anti-QS activity 
against Chromobacterium violaceum, a Gram-negative bacteria with AHLs mediated QS [47]. The (-) epicatechin gallate (Figure 2E) at sublethal concentrations inhibits two of the major determinants of virulence in S. aureus, the $\alpha$-toxin and the coagulase [48]. Furthermore, it has been shown that in combination with $\beta$-lactams, it is efficient to eliminate multiresistant strains of $S$. aureus. Although it has been observed that some synthetic analogs have better pharmacokinetic properties than the native (-) epicatechin gallate $[49,50]$.

\subsection{Cinnamaldehyde and related compounds}

Cinnamaldehyde $(\mathrm{CN})$ (Figure 3A) is a major constituent of cinnamon essential oils and occurs naturally in the bark and leaves of cinnamon trees of the genus Cinnamomum [51]. The antimicrobial activity of this compound has been proven $[52,53]$, but new studies have explored their anti-virulence properties, and in contrast to another compounds, it is considered a nontoxic substance widely used in food and in the cosmetic industry and their use is generally recognized as safe [54].

In P. aeruginosa, the acylated homoserine lactones (AHLs) are their main autoinducer molecules (Figure 1A) and the CN can inhibit their synthesis as well as the production of the phen-

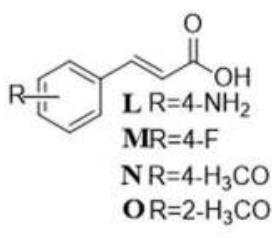<smiles>[X]c1ccc(O)cc1/C=C/C(=O)O</smiles><smiles>COc1cc(/C=C/C(=O)O)ccc1O</smiles><smiles>O=C(O)/C=C/c1ccc(O)c(O)c1</smiles><smiles>COc1ccc(/C=C/C=O)cc1</smiles><smiles>O=C/C=C/c1ccc(Cl)c(Cl)c1</smiles><smiles>CC(=O)/C=C/c1ccccc1</smiles>

E<smiles>CCCCCCC/C=C/C(C)=O</smiles>

H<smiles>O=C/C=C/c1ccc([N+](=O)[O-])cc1</smiles>

Figure 3. Cinnamaldehyde and related compounds with anti-virulence properties. A: Cinnamaldehyde, B: 2-nitrocinnamaldehyde, C: 4-methoxy-cinnamaldehyde, D: 3,4-dichloro-cinnamaldehyde, E: (E)-4-phenyl-3-buten-2-one, F: (E)-3-decen-2-one, G: 4N-4-nitrocinnamaldehyde, H: 4D-4-dimethylaminocinnamaldehyde, I: caffeic acid, J: ferulic acid, K: p-coumaric acid, L: TS027, M: TS110, N: 4-methoxy-cinnamic acid, O: trans-2-methoxy-cinnamic acid. 
azine, pyocyanin and swarming motility [55]. Remarkably, CN also has antitoxin production and anti-hemolytic activities [56]. Similarly, in C. violaceum, Yersinia entrerolitica and Erwinia carotovora, the concentration of AHLs was also reduced by $\mathrm{CN}$ and the mechanism proposed was the inhibition of synthesis or degradation transformation of the autoinducer [57].

The antibiofilm properties of $\mathrm{CN}$ have been widely documented; for example, in P. aeruginosa and in enterohemorrhagic Escherichia coli, this compound markedly abolished the biofilm formation in a dose-dependent manner by reducing the swarming motility and fimbriae production, respectively. In a previous report, it was shown that for the uropathogenic E. coli, $\mathrm{CN}$ prevented biofilm formation on plates and catheters, furthermore effectively inactivated preformed biofilms [54]. The mechanism proposed for the biofilm inhibition was related to the hydrophobicity of this compound, which helps to target lipids located in the bacterial cell membrane and mitochondria, increasing the membrane permeability, leading to the leakage of ions and other cell contents [54,58]. The foodborne pathogen Listeria monocytogenes forms biofilm for persistence and survives in which $\mathrm{CN}$ has inhibitory effect on formation and inactivating mature biofilm by means of the down-regulated critical genes for biofilm formation in this bacteria [59].

In Vibrio harveyi, the autoinducer-2 (A2) is also blocked by $\mathrm{CN}$ in a concentration-dependent way by decreasing the binding ability of the autoinducer to its response regulator protein. Between cinnamaldehyde derivatives, the 2-nitro-cinnamaldehyde (Figure 3B) was the most active compound yielding an inhibition of A2 similar to CN [60]. Similarly, the 2-nitro-cinnamaldehyde and 4-methoxy-cinnamaldehyde (Figure 3C) inhibit pigment production and protease activity in Vibrio anguillarum [60]. The $\mathrm{CN}$ is an aromatic carboxylic acid, and its inhibitory was highly dependent on the substitution pattern of the aromatic ring. Replacement of the dimethylamine $\left(\mathrm{Me}_{2} \mathrm{~N}\right)$ substituent with a methoxy $(\mathrm{MeO})$ or a nitro $\left(\mathrm{NO}_{2}\right)$ group enhanced the activity [60].

Various cinnamaldehyde analogs were also evaluated against Vibrio spp. The most active compounds were 2-nitro-cinnamaldehyde, 3, 4-dichloro-cinnamaldehyde (Figure 3D), (E)-4-phenyl-3buten-2-one (Figure 3E) and (E)-3-decen-2-one (Figure 3F), which show inhibitory activity in A2, bioluminescence, pigment and protease production [61]. In this case, also the inhibitory effect of cinnamaldehyde analogs was dependent on the structure, and analogs in which the aromatic ring was replaced by an alkyl moiety, but which still contain the acrolein group, proved also to be active inhibitors [61]. In general, the inhibitory effect of cinnamaldehyde analogs is highly dependent on the nature and degree of substitution of the aromatic ring, and the substituents with electron-withdrawing properties increase its activity. The $\mathrm{CN}$ and their analogs furthermore proved to be active blockers of virulence in vivo in different models, suggesting that they may have potential for therapeutic applications in humans and animals [61].

The CN also has inhibitory activity on biofilm formation in a methicillin-resistant Staphylococcus aureus at dose-dependent manner and represses the expression of $\operatorname{sar} A$, a gene implicated in the regulation of its biofilm [51]. In Streptococcus pyogenes, when the biofilm was treated with CN and their derivatives the 2-nitro-cinnamaldehyde (Figure 3B), 4N-4-nitrocinnamaldehyde (Figure $3 \mathrm{G}$ ) and 4D-4-dimethylaminocinnamaldehyde (Figure 3H), the biomass, average thickness and 
colony size at substratum were decreased and the molecular docking shows sequence and structure similarity with the active site for QS inhibition [62].

Among the cinnamaldehyde-related molecules, the caffeic acid (CA) (Figure 3I) and ferulic acid (FA) (Figure 3J) have shown antibiofilm properties. CA is the first phenolic acid compound that has been reported to have inhibitory activity on biofilm formation in Staphylococcus epidermis by a mechanism that did not involve bacterial death [63]. The potential of FA to control biofilm formation has been demonstrated by the reduction in mass and metabolic activity in Escherichia coli and Listeria monocytogenes biofilms, and also this compound caused the total inhibition of motility in both bacteria and the colony spreading in S. aureus; a form of passive bacterial movement was also inhibited [64].

The QS inhibitory activity of CA and FA also was evaluated in C. violaceum, and the results revealed that the activity was mediated by their ability to modulate AHL activity and synthesis [47]. Other related compound the p-coumaric acid (Figure 3K) showed QS inhibition in reporter strains like C. violaceum, Agrobacterium tumefaciens and Pseudomonas chlororaphis [65]. In addition, it represses the expression of regulatory genes of the T3SS of the phytopathogenic bacteria Dickeya dadantti, and for this activity, its hydroxyl group on the phenyl ring and the double bond are important [66]. Some of their derivatives such as TS027 (Figure 3L) and TS110 (Figure 3M) also repress the expression of T3SS regulatory genes and inhibit T3 effector protein in P. aeruginosa without affecting its growth [67]. While the cinnamic acid and 4-methoxy-cinnamic acid (Figure 3N) suppress the expression of T3SS in Erwinia amylovora [68], the o-coumaric acid (isomer of 3M) and trans-2-methoxy-cinnamic acid (Figure 3O) suppress translocation of two effector proteins of T3SS in Xanthomonas oryzae [69].

\subsection{Coumarin and related compounds}

The coumarins are compounds that have caused great interest for their pharmacological properties such as anti-inflammatory, antitumor, antioxidant and bactericidal activity [70]. Moreover, recently it has also documented that they possess anti-virulence properties. The coumarin (Figure 4A) and umbelliferone (Figure 4B) inhibit biofilm formation of E. coli, without affecting its growth. By a transcriptional analysis, it was identified that these phenols act by repressing genes related to curli production and motility, which causes a decrease in the production of fimbriae and swarming [71]. For these molecules, the hydroxylation of coumarin is an important determinant for their antibiofilm activity, since the position of hydroxyl groups as well as their number affects the antibiofilm compound activity [71].

Similarly, the presence of characteristic functional groups promotes the effective inhibition of virulence factors, as in the case of the furocoumarins [72], dihydroxybergamottin (Figure 4C) and bergamottin (Figure 4D), which exhibit anti-quorum-sensing effect on the AI-1 and AI-2 systems in Vibrio harveyi. Similarly, these furocoumarins inhibit biofilm formation of $E$. coli, $V$. harveyi, Salmonella typhimurium and P. aeruginosa without affecting bacterial growth. Although their mechanism of action is unknown, it is suggested that the presence of a furan residue could be acting as a competitive inhibitor for binding with the receptor protein of natural bacterial autoinducers [72]. 

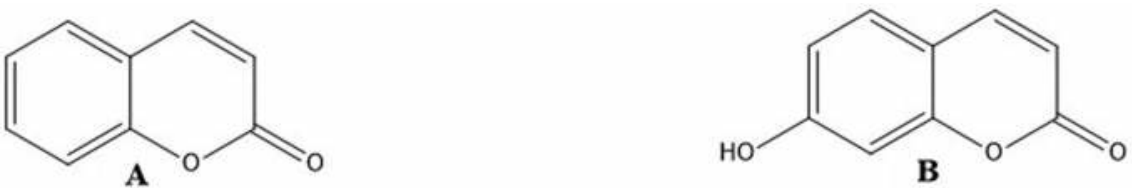<smiles>C/C(=C\COc1c2ccoc2cc2oc(=O)ccc12)CCC(O)C(C)(C)O</smiles><smiles>CC(C)=CCC/C(C)=C/COc1c2ccoc2cc2oc(=O)ccc12</smiles>

Figure 4. Coumarin and related compounds with anti-virulence properties. A: Coumarin, B: umbelliferone, C: dihydroxybergamottin, D: bergamottin.

\subsection{Curcumin and related compounds}

The major constituent of turmeric (Curcuma longa L.) roots/rhizomes is the curcumin (CUR) (Figure 5A), which is an active compound that showed an important antimicrobial activity $[73,74]$, but several studies also corroborate their inhibitory activity against virulence factors in pathogenic bacteria.<smiles>COc1cc(/C=C/C(=O)CC(=O)/C=C/c2ccc(O)cc2)ccc1O</smiles><smiles>COc1cc(/C=C/C(=O)CC(=O)/C=C/c2ccc(O)cc2)ccc1O</smiles><smiles>CCC(=O)/C=C/c1ccc(O)cc1</smiles>

Figure 5. Curcumin and related compounds with anti-virulence properties. A: Curcumin, B: demethoxycurcumin, C: bisdemethoxycurcumin. 
The secretion of sortase A (SrtA) a surface protein in S. aureus involved in bacterial adhesion for pathogenesis was inhibited by CUR, and also on in vivo assays, this compound reduces the capacity of bacteria to adhere to surfaces in a dose-dependent manner [75]. The other derivatives present in turmeric extract are demethoxycurcumin (Figure 5B) and bisdemethoxycurcumin (Figure 5C), which show inhibitory activity of SrtA [75]. Similarly, in Streptococcus mutans CUR inhibited the activity of SrtA and other proteins implicated in bacterial adhesion reducing the biofilm formation in this bacteria $[76,77]$. The diverse biological properties of CUR and its derivatives are attributed to the hydroxyl and phenol groups in the molecule [78], and structure-activity relationship studies suggest that a hydroxy group at the para-position is most critical for the expression of biological activity in these compounds [79].

The antibiofilm activity of CUR against uropathogens such as E. coli, Proteus mirabilis and Serratia marcescens was evaluated, and the results showed that their biofilm maturation was disturbed by a biomass reduction and by the interruption of swimming motility [80]. In clinical isolates of Klebsiella pneumoniae, the treatment with CUR was also effective for biofilm inhibition [81] as well in enterohemorrhagic E. coli [82]. In the same way, in Vibrio spp. the inhibitory effect on biofilm formation with the CUR treatment depends on the disruption of the maturation of biofilms and in the reduction of swimming and swarming motility. Further, this compound significantly represses other virulence factors like alginate and exopolysaccharide production and also inhibits bioluminescence. These inhibitory effects were also demonstrated on in vivo models in which CUR enhanced the survival rate of Artemia nauplii against Vibrio harveyi [83].

Diverse virulence factors in $P$. aeruginosa were inhibited by CUR, specifically the elastase, protease and pyocyanin production without affecting bacterial growth in a dose-dependent manner. The biofilm inhibition effect was demonstrated in vivo using Arabidopsis thaliana, where the treatment with CUR caused a reduction in the plant mortality by suppressing biofilm formation [84]. In the pathogenicity model using Caenorhabditis elegans, CUR demonstrate their anti-infective properties by reducing the nematode mortality [84]. Additionally, in $P$. aeruginosa and $C$. violaceum, CUR showed an anti-quorum sensing activity by inhibiting the production of acyl homoserine lactones [84].

\subsection{Eugenol and related compounds}

Eugenol (EG) (Figure 6A) is a major component of clove oil that possesses various biological properties [85], and their anti-virulence activity also has been evaluated. In pathogenic bacteria that secreted a broad spectrum of virulence factors that contribute to their pathogenicity,

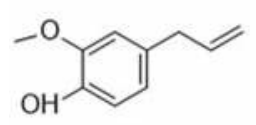

A

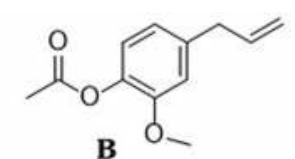

B

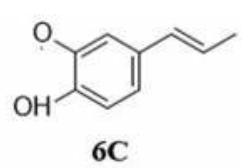

Figure 6. Eugenol and related compounds with anti-virulence properties. A: Eugenol, B: eugenyl acetate, C: isoeugenol, D: methyl eugenol. 
EG showed inhibitory activity. For example, in the nosocomial pathogen S. aureus, the hemolysin, staphyloxanthin, toxic shock syndrome toxin 1 (TSST-1) and enterotoxins are the most important virulence factors that were remarkably affected by EG [85]. The expression of virulence-related genes (sea, seb, tst and hla) was also decreased after the treatment with this compound [85].

In a methicillin-resistant (MRSA) and methicillin-sensitive (MSSA) S. aureus at subinhibitory concentration, EG eradicates pre-established biofilms and inhibited the colonization of this bacteria in a rat middle ear model, decreasing biofilm in biomass, cell viability and the expression of biofilm-related genes (icaD, sarA and seA), resulting in a low accumulation of polysaccharides and poorly adhesion of cells within biofilms [86]. The biofilm eradication effect of EG was mediated by two mechanisms: bacterial lysis within biofilms and by the disruption of cell-to-cell connections, hence dismantling the biofilm organization, which can be attributed to the hydrophobic and the lipophilic nature of their chemical structure [86].

The biofilm formation and biofilm-related genes in L. monocytogenes and E. coli also were inhibited by EG at dose-dependent manner $[56,59]$. In $P$. aeruginosa, although EG was unable to inhibit biofilm formation, it markedly reduced the production of pyocyanin, fimbriae production, hemolytic activity and other QS-controlled virulence factors in this bacterium such as the pseudomonas quinolone signal (PQS) [56]. Other study showed that EG at subinhibitory concentrations has QS inhibitory activity in P. aeruginosa and C. violaceum [87].

Moreover, derivatives of EG eugenyl acetate (EA) (Figure 6B), isoeugenol (IE) (Figure 6C) and methyl eugenol (ME) (Figure 6D) showed anti-virulence properties against pathogenic bacteria. In S. aureus, EA inhibited the production of virulence factors like hemolysin and staphyloxanthin. Similarly, in P. aeruginosa the pyocyanin, pyoverdin and exoprotease production were significantly reduced after the treatment with EA, and it also exhibited QS inhibitory potential in C. violaceum [88]. The other derivatives, IE and ME, also presented QS inhibitory against $P$. aeruginosa and $C$. violaceum $[89,90]$, and in the case of $V$. harveyi, ME have anti-bioluminescence activity [90]. These anti-virulence properties can be attributable to the presence of numerous substituted aromatic molecules like in the case of other phenols [85].

\subsection{Long-chain phenols}

Long-chain phenols are a group of metabolites which have extensively studied antitumor, antimicrobial and antioxidant activities; they are also of great interest to the industry because they are used to manufacture different chemicals [91]. Also, different long-chain phenols reported have different anti-virulence properties.

Our research group identified a mixture of four anacardic acids (AA) capable of inhibiting QS in C. violaceum and also able to reduce the production of virulence factors such as pyocyanin, rhamnolipids and elastase activity in P. aeruginosa [92]. Similarly, another mixture of AA (Figure 7A) and one of cardanols (Figure 7B) was capable of inhibiting P. aeruginosa biofilms. Notably, although the antibiofilm mechanism is not known, the polymerization of the AA (Figure 7C) slightly potentiates the activity [36]. Similarly, the maximum antibiofilm activity observed for this phenol was around $80 \%$ inhibition, which is reduced to $50 \%$ by the 

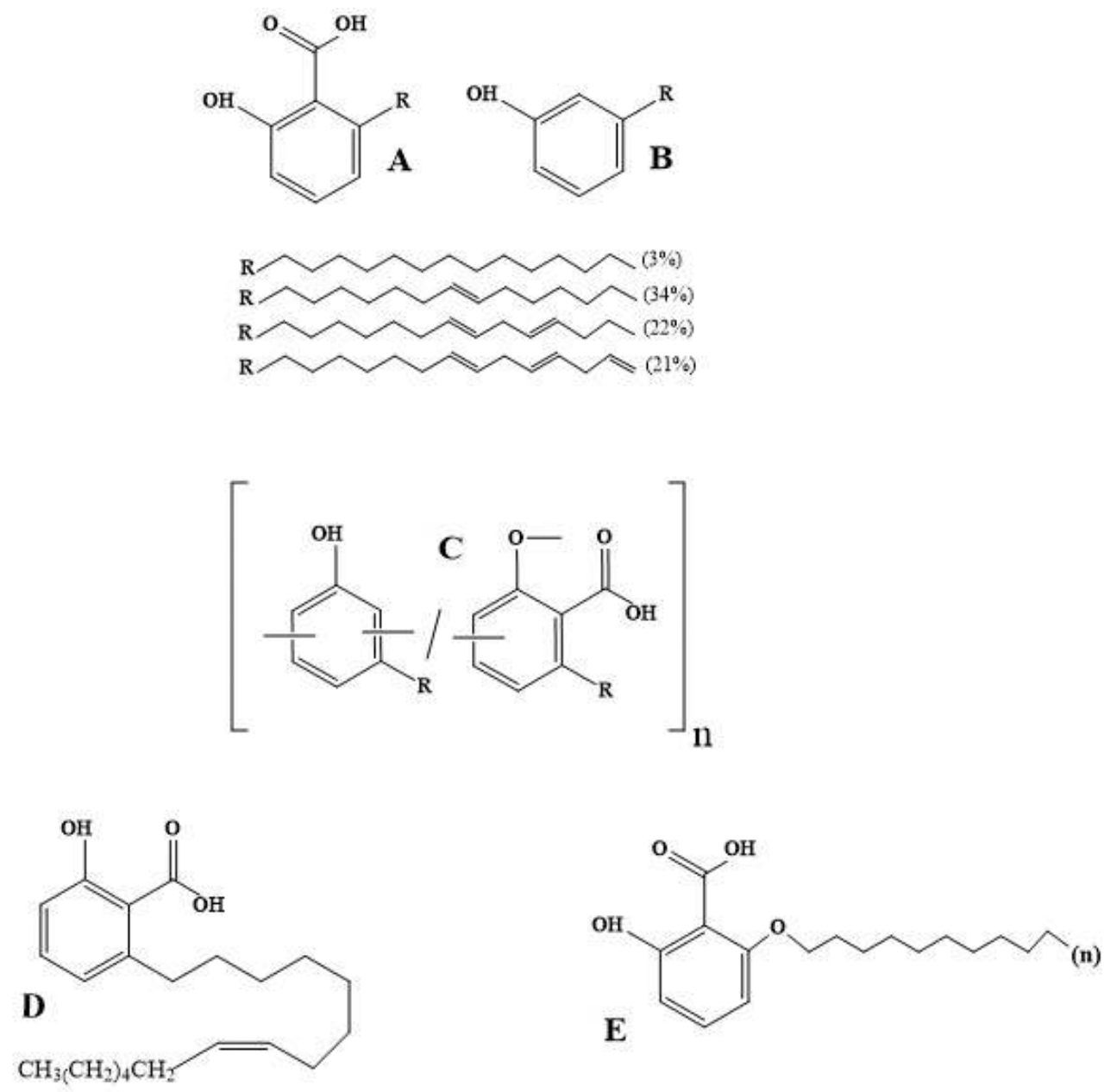

Figure 7. Long-chain phenols with anti-virulence properties. A: Anacardic acid mixture, B: cardanol mixture, C: polyanacardic acid, D: ginkgolic acids C15:1, E: 6-oxa isosteres of anacardic acids.

presence of a carboxyl group (salicylic acid) and only increases with the addition of an alkyl chain [36]. Hence, the incorporation of different types of alkyl chain in the meta-position of the salicylic acid seems to play a role in its activity, but this needs to be investigated in more detail.

Similarly, the antibiofilm activity of gingolic acids was reported, specifically the C15:1 (Figure 7D) abolished biofilm production without affecting bacterial viability, as well as reduced fimbriae production in enterohemorrhagic E. coli [93]. Transcriptomic analysis by DNA microarrays and qRT-PCR demonstrated that C15: 1 represses expression of genes involved in the synthesis of curli [93]. 
Furthermore, although mixtures of such compounds have shown anti-virulence activity, separation is laborious and costly, so their chemical syntheses become an attractive alternative. In this regard, AA synthetic (6-oxa isosteres) C: 11-C: 16 (Figure 7E) showed inhibition of TCS (KinA/SpoOF and NRII/NRI) [94]. Interestingly, AA with alkyl chains outside this range are not active [94]. Likewise, for this activity, the presence of the carboxyl group is important, as the C:12 and C:14 completely lose their effect, and the presence of phenolic $\mathrm{OH}$ partially restores it. Long-chain phenols are a group of natural products with great structural diversity, which represent an important potential source of molecules with anti-virulence activity.

\subsection{Quercetin and related compounds}

Various biological activities including anti-cancer, antibacterial, hepatoprotective, antiinflammatory and antiviral activities have been attributed to flavonoids [95]; moreover, recent studies have shown that various flavonoids also have anti-virulence activity.

Flavonoids like flavone (Figure 8A), quercetin (Figure 8B), apigenin (Figure 8C) and fisetin (Figure 8D) decrease blood hemolysis induced by S. aureus. Specifically, for flavone it was elucidated that its activity is due the repression of the transcription of $\alpha$-hemolysin genes (hla) and the global regulator gene (Sae) [96].

In addition, antibiofilm activity in S. aureus by quercetin (Figure 8B), chrysin (Figure 8E), apigenin (Figure 8C), kaempferol (Figure 8F) and fisetin (Figure 8D) has been reported where the number of hydroxyls is directly related to the increase in the activity [97], whereas morin (Figure 8G), myricetin (Figure 8H), quercetin (Figure 8B) and kaempferol (Figure 8F), having a hydroxyl group at $\mathrm{C}^{\prime} 2^{\prime}$ and $\mathrm{C}-4^{\prime}$ in ring B, inhibit SrtA and SrtB sortases of S. aureus more effectively [98].

The myricetin (Figure $\mathbf{8 H}$ ) is a compound able to interact with listeriolysin $\mathrm{O}$, a virulence factor of Listeria monocytogenes that is involved in the lysis of host cells. This interaction is related to the presence of the double bond in the molecule, specifically in the $\mathrm{C} 1-\mathrm{C} 2$ position in ring C [99]. This generates a complex that blocks the hemolytic activity of the listeriolysin as it prevents binding to cholesterol.

Furthermore, it has been shown that the naringenin (Figure 8I) have antibiofilm activity on $V$. harveyi and E. coli; however, this activity is compromised when sugar residues are incorporated [100]. In the case of V. harveyi, the naringenin also represses the expression of T3SS regulatory genes [100].

\subsection{Resveratrol and related compounds}

Resveratrol (RV) (Figure 9A) is a natural polyphenol and phytoalexin produced by plants in case of attacks by pathogens [101]. It is mainly found in the skin of grapes, some berries and red wine [102]. For its medical properties, it is recognized as a compound that provides multiple benefits to human health [103] and recent studies have demonstrated its anti-virulence potential. 
<smiles>O=C1CC(c2ccc(O)cc2)Oc2cc(O)cc(O)c21</smiles><smiles>O=c1c(O)c(-c2ccc(O)c(O)c2)oc2cc(O)cc(O)c12</smiles><smiles></smiles><smiles>O=c1c(O)c(-c2cc(O)c(O)c(O)c2)oc2cc(O)cc(O)c12</smiles><smiles>O=c1cc(-c2ccccc2)oc2ccccc12</smiles><smiles>O=C(CCc1ccc(O)cc1)c1ccc(O)cc1O</smiles><smiles></smiles><smiles>O=c1c(O)c(-c2ccc(O)cc2)oc2cc(O)cc(F)c12</smiles><smiles>O=c1cc(-c2ccccc2)oc2cc(O)cc(O)c12</smiles>

Figure 8. Quercetin and related compounds with anti-virulence properties. A: Flavone, B: quercetin, C: apigenin, D: fisetin, E: chrysin, F: kaempferol, G: morin, H: myricetin, I: naringenin.

Since plants produce RV, this metabolite was identified as the active compound with inhibitory activity against biofilm formation in Propionibacterium acnes from extracts of plants used in traditional Chinese medicine [104]. Also in S. aureus, the evaluation of different commercial red wines showed a dose-dependent inhibition of biofilm formation, hemolytic activity and increase in the survival of Caenorhabditis elegans exposed to the bacteria [97]. One of the major constituents of these red wines was RV, and similarly, it inhibited hemolysis in S. aureus [97]. In Vibrio cholerae, the biofilm formation has a prominent role in pathogenesis and RV was found to be a potent biofilm inhibitor at subinhibitory concentrations and showed binding affinity with the virulence activator AphB [102]. Furthermore, in the uropathogenic bacteria, Proteus mirabilis RV inhibited swarming motility, hemolysin and urease activity as well as the virulence factor expression at dose-dependent manner [101].

Compounds related to RV, the oxyresveratrol (Figure 9B), dicinnamyl (Figure 9C), cis-stilbene (Figure 9D) and trans-stilbene (Figure 9E) also were evaluated against $S$. aureus virulence. 
<smiles>Oc1cc(O)cc(C=Cc2cc(O)ccc2O)c1</smiles><smiles>C(C=CC=Cc1ccccc1)=CC=Cc1ccccc1</smiles>

C

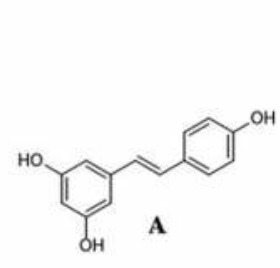

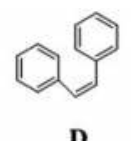

D

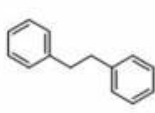

$\mathbf{E}$

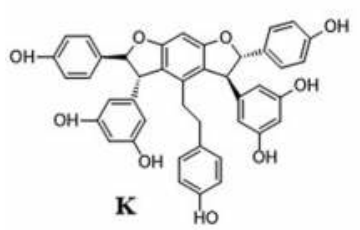

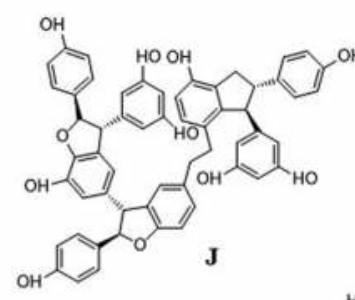
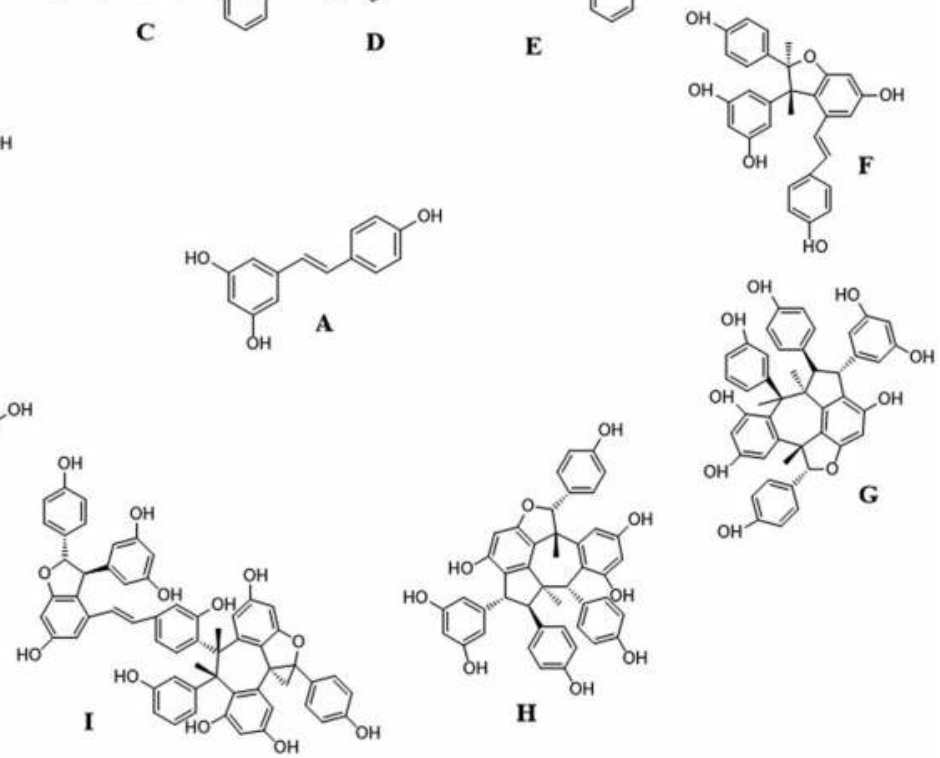

Figure 9. Resveratrol and related compounds with anti-virulence properties. A: Resveratrol, B: oxyresveratrol, C: dicinnamyl, D: cis-stilbene, E: trans-stilbene, F: $\varepsilon$-viniferin, G: suffruticosol A, H: suffruticosol B, I: vitisin A, J: vitisin B, and K: trans-gnetin.

Only, the cis-stilbene and trans-stilbene along with RV markedly inhibited the hemolytic activity by more than $80 \%$, while dicinnamyl, oxyresveratrol and trans-stilbene have a significant biofilm inhibition effect [105]. The inhibitory activity of trans-stilbene was corroborated with the evidence that is able to repress the expression of the $\alpha$-hemolysin gene $(h l a)$ and of genes implicated in adhesion (icaA and icaD) and with the attenuation of $S$. aureus virulence in the nematode C. elegans [105]. In enterohemorrhagic E. coli, the RV isolated from the extract of Carex dimorpholepis significantly reduced biofilm formation (up to 90\%), expression of biofilmrelated genes and swimming and swarming motilities, suggesting that this compound is a major antibiofilm component in this extract, corroborating its potential as therapeutic agent against E. coli [106].

The RV and its oligomers, namely $\varepsilon$-viniferin (Figure 9F), suffruticosol A (Figure 9G), suffruticosol B (Figure 9H), vitisin A (Figure 9I) and vitisin B (Figure 9J) isolated from different plant families, also have antibiofilm activities against $E$. coli. The qRT-PCR analyses showed that $\varepsilon$-viniferin, suffruticosol $B$ and vitisin $B$ repress the expression of genes involved in curli and fimbriae production [105]. Also, RV and suffruticosol $A$, suffruticosol $B$, vitisin $A$ and $B$ inhibit biofilm formation in P. aeruginosa at dose-dependent manner [106].

The oligomers $\varepsilon$-viniferin and trans-gnetin (Figure 9K) isolated from Paeonia lactiflora have inhibitory activity in neuraminidase activity, an enzyme involved in many pathological process in 
tropical human pathogens [107]. Furthermore, the $\varepsilon$-viniferin and RV isolated from Carex pumila extract also demonstrated significantly biofilm inhibition in P. aeruginosa and E. coli [108]. The anti-quorum sensing activity of RV also was demonstrated, in C. violaceum, since it reduces violacein production [57, 109]. In Yersinia enterolitica and Erwinia amylovora, it was one of the most active compounds that can reduce the concentration of the autoinducers due to degradation transformation or inhibition of synthesis [57].

\subsection{Salicylic acid and related compounds}

Salicylic acid (SA) (Figure 10A) is a phenolic compound synthesized by plants that play an important role in the regulation of various physiological processes [110, 111], and in recent years, their inhibitory activity against bacterial virulence has been reported.

Several studies have demonstrated that SA has inhibitory activity in the motility and production of extracellular virulence factors in the opportunistic pathogenic bacteria P. aeruginosa, and among those factors, pyocyanin was inhibited by approximately $80 \%$ by SA and decreased the elastase and exoprotease production [110]. Similarly, a subinhibitory concen-<smiles>CC(=O)Oc1ccccc1C(=O)O</smiles><smiles>NC(=O)c1ccccc1O</smiles><smiles>COC(=O)c1ccccc1O</smiles><smiles>O=C(O)c1cc(O)c(O)c(O)c1</smiles><smiles>O=C(O)c1ccccc1O</smiles><smiles>O=C(O)c1ccccc1</smiles>

A<smiles>COc1cc(C(=O)O)ccc1O</smiles><smiles>O=C(O)c1ccc(O)c(O)c1</smiles><smiles>O=C(O)c1ccc(O)cc1</smiles>

Figure 10. Salicylic acid and related compounds with anti-virulence properties. A: Salicylic acid, B: acetyl salicylic acid, C: salicylamide, D: methyl salicylate, E: benzoic acid, F: $p$-hydroxybenzoic acid, G: protocatechuic acid, H: vanillic acid, I: gallic acid. 
tration of SA inhibited the twitching and swimming motility as well as the invasion and acute cytotoxicity of $P$. aeruginosa in corneal epithelial cells [112]. Some derivatives of SA, including acetyl salicylic acid (Figure 10B), salicylamide (Figure 10C), methyl salicylate (Figure 10D) and a precursor of SA, benzoic acid (Figure 10E), were evaluated, and the inhibition levels observed were comparable with those obtained with SA for the same virulence factors [110]. SA is a benzoic acid that possesses an aromatic ring bearing a hydroxyl group, and probably, one of these components of the structure is responsible for its anti-virulence activity.

The biofilm formation in P. aeruginosa was also inhibited by SA in vitro and in vivo decreasing the attachment and consequently the biofilm formation [36, 110]. Similarly, in other bacterial pathogenic species that form biofilms, SA has inhibitory activity; for example, in Streptococus mutans, the biofilm formation was highly decreased when the enzymes, glucosyl and fructosyl transferases, which synthetize extracellular polymeric substances, were inhibited by SA [113].

Compounds related to SA, the p-hydroxybenzoic acid (Figure 10F) and protocatechuic acid (Figure 10G) at growth subinhibitory concentrations have different modes of action on biofilm formation disruption in Staphylococcus species [114]. Also, for the bacteria Helicobacter pylori implicated in the development of peptic ulcer, duodenal ulcer and gastric cancer, which uses a urease enzyme for the basification of the stomach $\mathrm{pH}$ and hence the colonization of the gastric mucosa [115], the protocatechuic acid has an inhibitory effect of $40 \%$ in its urease activity [116]. Vanillic acid (4-hydroxy-3-methoxybenzaldehyde) (Figure 10H) also showed antibiofilm activity in Aeromonas hydrophila at all the concentrations used in the range of $0-0.250 \mathrm{mg} / \mathrm{mL}$ [117].

Other important hydroxy benzoic acid with a numerous reports of anti-virulence properties is gallic acid (GA) (Figure 10I), which shows inhibition in many virulence factors among bacteria. For example, in $S$. aureus, GA reduces the bacterial adhesion and biofilm formation as well as the production of $\alpha$-hemolysin a virulence factor produced by the bacteria with hemolytic, cytotoxic, dermonecrotic and lethal properties [118] since its activity was inhibited in a dose-dependent manner by this compound [119]. Similarly, in P. aeruginosa, E. coli and Listeria monocytogenes, their biofilm formation was also inhibited by GA.

The inhibitory activity showed by these compounds may be related to some of their structural features, since different reports mentioned that in the active phenolic compounds, the basic skeleton remains the same, the basic skeleton remains same, but the number and positions of the hydroxyl groups on the aromatic ring and the type of substituents provide different biological properties [120-122]. Also, SA, gallic acid and vanillic acid have QS inhibitory activity by two different mechanisms: first, by affecting the synthesis of AHLs [55, 57, 123] and second, by interfering with the binding of short-chain AHLs to their receptor, especially in the case of vanillic acid [117].

\section{Conclusion and future perspective}

An important feature of the anti-virulence molecules is that they may be less prone to promote the emergence of resistance than conventional antibiotics. At the moment, phenolic compounds represent the largest number of natural products with anti-virulence-reported activity and whose main target has been the inhibition of QS and biofilms. However, it has 
also been found that they can directly inhibit some of virulence factors such as sortases, curli, type III secretion system (T3SS), fimbriaes and two-component regulatory systems. It should be noted that most of the phenolic compounds represent structures already known, several of which have been subject to different pharmacological studies and some are even part of the international pharmacopeia and are active ingredients of herbal medicines.

Moreover, although QS is considered the main regulator of bacterial virulence, this is still part of a complex network of interconnected components including several environmental regulation systems and QS-independent virulence factors. Also, the direct inhibition of virulence factors and regulators of QS and TCS represents interesting options for achieving the implementation of this strategy. Thus, the correct design of anti-virulence therapies is very important [124, 125], and a feasible option is the combination of drugs with different action targets. In the same way, some challenges to overcome involve the evaluation of anti-virulence compounds in most bacterial systems, the corroboration in vivo in animal infection models and finally the evaluation of possible side effects on the populations of commensal and symbiotic bacteria.

Given the growing public health problem worldwide derived by the emergence of bacterial multiresistance to antibiotics, the development of suitable anti-virulence therapies is presented as a viable strategy to provide a solution to this problem; moreover, we are in the decisive years that will dictate the implementation of these kind of strategies, this is occurring in a period of resurgence of the interest in natural products activities in which phenolic compounds have a fundamental role.

\section{Acknowledgements}

This work was supported by grants from Scientific Development Projects for Solving National Problems/CONACyT Mexico no. 2015-01-402. N-MC research is supported by the CONACYT PhD Grant 376049 and M-PL by the CONACYT PhD Grant 302218. R-GC research is funded by SEP-CONACYT 152794 and by PAPIIT-UNAM IA201116. I-CJ research is supported by Fideicomiso-COLPOS 167304 and Cátedras-CONACyT program.

\section{Author details}

Naybi Muñoz-Cazares ${ }^{1+}{ }^{+}$, Rodolfo García-Contreras ${ }^{2+}{ }$, Macrina Pérez-López ${ }^{1}$ and Israel Castillo-Juárez ${ }^{1 *}$

*Address all correspondence to: israel.castillo@colpos.mx

1 Department of Botany, Postgraduate College, Texcoco, Mexico

2 Department of Microbiology and Parasitology, Faculty of Medicine, UNAM, Mexico City, Mexico

† Authors contributed equally to this work 


\section{References}

[1] Aminov R.I. A brief history of the antibiotic era: lessons learned and challenges for the future. Front Microbiol. 2010;1:134. doi:10.3389/fmicb.2010.00134

[2] López-Pueyo M.J., Barcenilla-Gaite F., Amaya-Villar R., Garnacho-Montero J. Antibiotic multiresistance in critical care units. Med Intensiva. 2011;35(1):41-53. doi:10.1016/j. medin.2010.07.011

[3] Spellberg B., Guidos R., Gilbert D., Bradley J., Boucher H.W., Scheld W.M., et al. The epidemic of antibiotic-resistant infections: a call to action for the medical community from the Infectious Diseases Society of America. Clin Infect Dis. 2008;46(2):155-164. doi:10.1086/524891

[4] Aryee A., Price N. Antimicrobial stewardship - can we afford to do without it? Br J Clin Pharmacol. 2015;79(2):173-181. doi:10.1111/bcp.12417

[5] Rangel-Vega A., Bernstein L.R., Mandujano-Tinoco E.A., García-Contreras S.J., GarcíaContreras R. Drug repurposing as an alternative for the treatment of recalcitrant bacterial infections. Front Microbiol. 2015;6:282. doi:10.3389/fmicb.2015.00282

[6] Finlay J., Miller L., Poupard J.A. A review of the antimicrobial activity of clavulanate. J Antimicrob Chemother. 2003;52(1):18-23. doi:10.1093/jac/dkg286

[7] Tegos G.P.,Haynes M., Strouse J.J., Khan M.M., Bologa C.G., Oprea T.I., Sklar L.A. Microbial efflux pump inhibition: tactics and strategies. Curr Pharm Des. 2011;17(13):1291-1302.

[8] Ueda A., Attila C., Whiteley M., Wood T.K. Uracil influences quorum sensing and biofilm formation in Pseudomonas aeruginosa and fluorouracil is an antagonist. Microb Biotechnol. 2009;2(1):62-74. doi:10.1111/j.1751-7915.2008.00060.x

[9] Kwan B.W., Chowdhury N., Wood T.K. Combatting bacterial infections by killing persister cells with mitomycin C. Environ Microbiol. 2015;17(11):4406-4414. doi:10.1111/ 1462-2920.12873

[10] Chowdhury N., Wood T.L., Martínez-Vázquez M., García-Contreras R., Wood T.K. DNA-crosslinker cisplatin eradicates bacterial persister cells. Biotechnol Bioeng. 2016;113(9):1984-1992. doi:10.1002/bit.25963

[11] Abedon S.T., Kuhl S.J., Blasdel B.G., Kutter E.M. Phage treatment of human infections. Bacteriophage. 2011;1(2):66-85. doi:10.4161/bact.1.2.15845

[12] Young R., Gill J.J. Microbiology. Phage therapy redux - what is to be done? Science. 2015;350(6265):1163-1164. doi:10.1126/science.aad6791

[13] Maeda T., García-Contreras R., Pu M., Sheng L., Garcia L.R., Tomás M., et al. Quorum quenching quandary: resistance to antivirulence compounds. ISME J. 2012;6(3):493-501. doi:10.1038/ismej.2011.122

[14] García-Contreras R., Maeda T., Wood T.K. Resistance to quorum-quenching compounds. Appl Environ Microbiol. 2013;79(22):6840-6846. doi:10.1128/AEM.02378-13 
[15] García-Contreras R., Maeda T., Wood T.K. Can resistance against quorum-sensing interference be selected? ISME J. 2016;10:4-10. doi:10.1038/ismej.2015.84

[16] García-Contreras R., Martínez-Vázquez M., Velázquez Guadarrama N., Villegas Pañeda A.G., Hashimoto T., Maeda T., et al. Resistance to the quorum-quenching compounds brominated furanone C-30 and 5-fluorouracil in Pseudomonas aeruginosa clinical isolates. Pathog Dis. 2013;68(1):8-11. doi:10.1111/2049-632X.12039

[17] Bjarnsholt T., Jensen P.Ø., Burmølle M., Hentzer M., Haagensen J.A., Hougen H.P, et al. Pseudomonas aeruginosa tolerance to tobramycin, hydrogen peroxide and polymorphonuclear leukocytes is quorum-sensing dependent. Microbiology. 2005;151(2):373-383. doi:10.1099/mic.0.27463-0

[18] García-Contreras R., Nuñez-López L., Jasso-Chávez R., Kwan B.W., Belmont J.A., Rangel-Vega A., et al. Quorum sensing enhancement of the stress response promotes resistance to quorum quenching and prevents social cheating. ISME J. 2015;9:115-125. doi:10.1038/ismej.2014.98

[19] Castillo-Juárez I., Maeda T., Mandujano-Tinoco E.A., Tomás M., Pérez-Eretza B., GarcíaContreras S.J., et al. Role of quorum sensing in bacterial infections. World J Clin Cases. 2015;3(7):575-598. doi:10.12998/wjcc.v3.i7.575

[20] Padilla-Chacon D., Castillo-Juárez I., Muñoz-Cázares N.R., García-Contreras R. Gene expression and enhanced antimicrobial resistance in biofilms. In: Book on the topic microbial biofilms in plant and soil health: fundamentals and current research. John Wiley \& Sons, Ltd.; 2016. In press

[21] Castillo-Juárez I., López-Jácome L.E., Soberón-Chávez G., Tomás M., Lee J., CastañedaTamez P. et al. Exploiting quorum sensing inhibition for the control of Pseudomonas aeruginosa and Acinetobacter baumannii biofilms. Curr Top Med Chem. In press.

[22] Mitrophanov A.Y., Groisman E.A. Signal integration in bacterial two-component regulatory systems. Genes Dev. 2008;22(19):2601-2611. doi:10.1101/gad.1700308

[23] Gotoh Y., Eguchi Y., Watanabe T., Okamoto S., Doi A., Utsumi R. Two-component signal transduction as potential drug targets in pathogenic bacteria. Curr Opin Microbiol. 2010;13(2):232-239. doi:10.1016/j.mib.2010.01.008

[24] Costerton J.W., Lewandowski Z., Caldwell D.E., Korber D.R., Lappin-Scott H.M. Microbial biofilms. Annu Rev Microbiol. 1995;49:711-745. doi:10.1146/annurev.mi.49.100195.003431

[25] Barnhart M.M., Chapman M.R. Curli biogenesis and function. Annu Rev Microbiol. 2006;60:131-147. doi:10.1146/annurev.micro.60.080805.142106

[26] Aiello D., Williams J.D., Majgier-Baranowska H., Patel I., Peet N.P., Huang J, et al. Discovery and characterization of inhibitors of Pseudomonas aeruginosa type III secretion. Antimicrob Agents Chemother. 2010;54(5):1988-1999. doi:10.1128/AAC.01598-09

[27] Gu L., Zhou S., Zhu L., Liang C., Chen X. Small-molecule inhibitors of the type III secretion system. Molecules. 2015;20(9):17659-17674. doi:10.3390/molecules200917659 
[28] Erhardt M. Strategies to block bacterial pathogenesis by interference with motility and chemotaxis. In: Current topics in microbiology and immunology. ed. Springer Berlin Heidelberg; 2016. p. 1-21. doi:10.1007/82_2016_493

[29] Knight S.D., Bouckaert J. Structure, function, and assembly of type 1 fimbriae. Top Curr Chem. 2009;288:67-107. doi:10.1007/128_2008_13

[30] Hendrickx A.P., Budzik J.M., Oh S.Y., Schneewind O. Architects at the bacterial surface-sortases and the assembly of pili with isopeptide bonds. Nat Rev Microbiol. 2011;9(3):166-176. doi:10.1038/nrmicro2520

[31] Spirig T., Weiner E.M., Clubb R.T. Sortase enzymes in Gram-positive bacteria. Mol Microbiol. 2011;82(5):1044-1059. doi:10.1111/j.1365-2958.2011.07887.x

[32] Martín-Rodríguez A.J., Quezada H., Becerril Aragón G., de la Fuente Núñez C., CastilloJuárez I, Maeda T, et al. Recent developments in novel bacterial anti-infectives. In: AttaUr-Rahman, editor. Frontiers in Clinical Drug Research-Anti-infectives. Dubai, UAE: Bentham Science Publishers; 2016.

[33] Nunes Silva L., Zimmer K.R., Macedo A.J., Trentin D.S. Plant natural products targeting bacterial virulence factors. Chem Rev. 2016;116(16):9162-9236. doi:10.1021/acs. chemrev.6b00184

[34] Mitscher L.A., Jung M., Shanke D.L., Dou J.H. Chemoprotection: a review of the potential therapeutic antioxidant properties of green tea (Camellia sinensis) and certain of its constituents. Med Res Rev. 1997;17(4):327-365. doi:10.1002/ (SICI)1098-1128(199707)17:4<327::AID-MED2>3.0.CO;2-Y

[35] Niedzwiecki A., Roomi M.W., Kalinovsky T., Rath M. Anticancer efficacy of polyphenols and their combinations. Nutrients. 2016;8(9):552. doi:10.3390/nu8090552

[36] Jagani S., Chelikani R., Kim D.S. Effects of phenol and natural phenolic compounds on biofilm formation by Pseudomonas aeruginosa. Biofouling. 2009;25(4):321-324. doi:10.1080/08927010802660854

[37] Lee P., Tan K.S. Effects of epigallocatechin gallate against Enterococcus faecalis biofilm and virulence. Arch Oral Biol. 2015;60(3):393-399. doi:10.1016/j.archoralbio.2014.11.014

[38] Blanco A.R., Sudano-Roccaro A., Spoto G.C., Nostro A., Rusciano D. Epigallocatechin gallate inhibits biofilm formation by ocular staphylococcal isolates. Antimicrob Agents Chemother. 2005;49(10):4339-4343. doi:10.1128/AAC.49.10.4339-4343.2005

[39] Huber B., Eberl L., Feucht W., Polster J. Influence of polyphenols on bacterial biofilm formation and quorum-sensing. Z Naturforsch C. 2003;58(11-12):879-884.

[40] Dell'Aica I., Donà M., Tonello F., Piris A., Mock M., Montecucco C, et al. Potent inhibitors of anthrax lethal factor from green tea. EMBO Rep. 2004;5(4): 418-422. doi:10.1038/ sj.embor.7400118

[41] Vandeputte O.M., Kiendrebeogo M., Rajaonson S., Diallo B., Mol A, et al. Identification of catechin as one of the flavonoids from Combretum albiflorum bark extract that reduces 
the production of quorum-sensing-controlled virulence factors in Pseudomonas aeruginosa PAO1. Appl Environ Microbiol. 2010;76(1):243-253. doi:10.1128/AEM.01059-09

[42] Xu X., Zhou X.D., Wu C.D. The tea catechin epigallocatechin gallate suppresses cariogenic virulence factors of Streptococcus mutans. Antimicrob Agents Chemother. 2011;55(3):1229-1236. doi:10.1128/AAC.01016-10

[43] Hattori M., Kusumoto I.T., Namba T., Ishigami T., Hara Y. Effect of tea polyphenols on glucan synthesis by glucosyltransferase from Streptococcus mutans. Chem Pharm Bull (Tokyo). 1990;38(3):717-720.

[44] Nakahara K., Kawabata S., Ono H., Ogura K., Tanaka T., Ooshima T., Hamada S. Inhibitory effect of oolong tea polyphenols on glycosyltransferases of mutans Streptococci. Appl Environ Microbiol. 1993;59(4):968-973.

[45] Xu X., Zhou X.D., Wu C.D. Tea catechin epigallocatechin gallate inhibits Streptococcus mutans biofilm formation by suppressing gtf genes. Arch Oral Biol. 2012;57(6):678-683. doi:10.1016/j.archoralbio.2011.10.021

[46] Castillo S., Heredia N., García S. 2(5H)-Furanone, epigallocatechin gallate, and a citric-based disinfectant disturb quorum-sensing activity and reduce motility and biofilm formation of Campylobacter jejuni. Folia Microbiol (Praha). 2015;60(1):89-95. doi:10.1007/s12223-014-0344-0

[47] Borges A., Serra S., Abreu C.A., Saavedra M.J, Salgado A., Simões M. Evaluation of the effects of selected phytochemicals on quorum sensing inhibition and in vitro cytotoxicity. Biofouling. 2014;30(2):183-195. doi:10.1080/08927014.2013.852542

[48] Shah S., Stapleton P.D., Taylor P.W. The polyphenol (-)-epicatechin gallate disrupts the secretion of virulence-related proteins by Staphylococcus aureus. Lett Appl Microbiol. 2008;46(2):181-185. doi:10.1111/j.1472-765X.2007.02296.x

[49] Anderson J.C., Headleya C., Stapletonb P.D.,Taylor P.W. Synthesis and antibacterial activity of hydrolytically stable (-)-epicatechin gallate analogues for the modulation of $\beta$-lactam resistance in Staphylococcus aureus. Bioorg Med Chem Lett. 2005;15(10): 26332635. doi:10.1016/j.bmcl.2005.03.063

[50] Anderson J.C., Headley C., Stapleton P.D., Taylor P.W. Asymmetric total synthesis of B-ring modified (-)-epicatechin gallate analogues and their modulation of $\beta$-lactam resistance in Staphylococcus aureus. Tetrahedron. 2005*******;61(32): 7703-7711. doi:10.1016/j. tet.2005.05.086

[51] Jia P., Xue Y.J., Duan X.J., Shao S.H. Effect of cinnamaldehyde on biofilm formation and sarA expression by methicillin-resistant Staphylococcus aureus. Lett Appl Microbiol. 2011;53(4):409-416. doi:10.1111/j.1472-765X.2011.03122.x

[52] Bowles B.L., Sackitey S.K., Williams A.C. Inhibitory effects of flavor compounds on Staphylococcus aureus WRRC B124. J Food Saf. 1995;15(4):337-347. doi:10.1111/j.17454565.1995.tb00144.x

[53] Gupta C., Garg A.P., Uniyal R.C., Kumari A. Comparative analysis of the antimicrobial activity of cinnamon oil and cinnamon extract on somefood-borne. Afr J Microbiol Res. 2008;2(9):247-251. 
[54] Amalaradjou M.A., Narayanan A., Baskaran S.A., Venkitanarayanan K. Antibiofilm effect of trans-cinnamaldehyde on uropathogenic Escherichia coli. J Urol. 2010;184(1):358363. doi:10.1016/j.juro.2010.03.006

[55] Chang C.Y., Krishnan T., Wang H., Chen Y., Yin W.F., Chong Y.M, et al. Non-antibiotic quorum sensing inhibitors acting against $\mathrm{N}$-acyl homoserine lactone synthase as druggable target. Sci Rep. 2014;4:7245. doi:10.1038/srep07245

[56] Kim Y.G., Lee J.H., Kim S.I., Baek K.H., Lee J. Cinnamon bark oil and its components inhibit biofilm formation and toxin production. Int J Food Microbiol. 2015;195:30-39. doi:10.1016/j.ijfoodmicro.2014.11.028

[57] Truchado P., Tomás-Barberán F. A., Larrosa M., Allende A. Food phytochemicals act as quorum sensing inhibitors reducing production and/or degrading autoinducers of Yersinia enterocolitica and Erwinia carotovora. Food Control. 2012;24(1-2):78-85. doi:10.1016/j.foodcont.2011.09.006

[58] Sikkema J., de Bont J.A., Poolman B. Interactions of cyclic hydrocarbons with biological membranes. J Biol Chem. 1994;269(11):8022-8028.

[59] Upadhyay A., Upadhyaya I., Kollanoor-Johny A., Venkitanarayanan K. Antibiofilm effect of plant derived antimicrobials on Listeria monocytogenes. Food Microbiol. 2013;36(1):7989. doi:10.1016/j.fm.2013.04.010

[60] Brackman G., Defoirdt T., Miyamoto C., Bossier P., Van Calenbergh S., Nelis H, et al. Cinnamaldehyde and cinnamaldehyde derivatives reduce virulence in Vibrio spp. by decreasing the DNA-binding activity of the quorum sensing response regulator LuxR. BMC Microbiol. 2008;8:149. doi:10.1186/1471-2180-8-149

[61] Brackman G., Celen S., Hillaert U., Van Calenbergh S., Cos P., Maes L, et al. Structureactivity relationship of cinnamaldehyde analogs as inhibitors of AI-2 based quorum sensing and their effect on virulence of Vibrio spp. PLoS One. 2011;6(1):e16084. doi:10.1371/ journal.pone.0016084

[62] Beema Shafreen R.M., Selvaraj C., Singh S.K., Karutha Pandian S. In silico and in vitro studies of cinnamaldehyde and their derivatives against LuxS in Streptococcus pyogenes: effects on biofilm and virulence genes. J Mol Recognit. 2014;27(2):106-116. doi:10.1002/jmr.2339

[63] Zimmer K.R., Blum-Silva C.H., Souza A.L., Wulffschuch M., Reginatto F.H., Pereira C.M, et al. The antibiofilm effect of blueberry fruit cultivars against Staphylococcus epidermidis and Pseudomonas aeruginosa. J Med Food. 2014;17(3):324-331. doi:10.1089/jmf.2013.0037

[64] Borges A., Saavedra M.J., Simões M. The activity of ferulic and gallic acids in biofilm prevention and control of pathogenic bacteria. Biofouling. 2012;28(7):755-767. doi:10.10 80/08927014.2012.706751

[65] Bodini S.F., Manfredini S., Epp M., Valentini S., Santori F. Quorum sensing inhibition activity of garlic extract and p-coumaric acid. Lett Appl Microbiol. 2009;49(5):551-555. doi:10.1111/j.1472-765X.2009.02704.x 
[66] Li Y.,Peng Q., Selimi D., Wang Q, Charkowski A.O., Chen X, et al. The plant phenolic compound p-coumaric acid represses gene expression in the Dickeya dadantii type III secretion system. Appl Environ Microbiol. 2009;75(5):1223-1228. doi:10.1128/AEM. 02015-08

[67] Yamazaki A., Li J., Zeng Q., Khokhani D., Hutchins W.C., Yost A.C,et al. Derivatives of plant phenolic compound affect the type III secretion system of Pseudomonas aeruginosa via a GacS-GacA two-component signal transduction system. Antimicrob Agents Chemother. 2012;56(1):36-43. doi:10.1128/AAC.00732-11

[68] Khokhani D., Zhang C., Li Y., Wang Q., Zeng Q., Yamazaki A, et al. Discovery of plant phenolic compounds that act as type III secretion system inhibitors or inducers of the fire blight pathogen, Erwinia amylovora. Appl Environ Microbiol. 2013;79(18):5424-5436. doi:10.1128/AEM.00845-13

[69] Fan S., Tian F., Li J., Hutchins W., Chen H., Yang F, et al. Identification of phenolic compounds that suppress the virulence of Xanthomonas oryzae on rice via the type III secretion system. Mol Plant Pathol. 2016. doi:10.1111/mpp.12415

[70] Jain P.K., Joshi H. Coumarin: chemical and pharmacological profile. J Appl Pharm Sci. 2012;02(06):236-240. doi:10.7324/JAPS.2012.2643

[71] Lee J.H., Kim Y.G., Cho H.S., Ryu S.Y., Cho M.H., Lee J. Coumarins reduce biofilm formation and the virulence of Escherichia coli O157:H7. Phytomedicine. 2014;21(8-9):10371042. doi:10.1016/j.phymed.2014.04.008

[72] Girennavar B., Cepeda M.L, Soni K.A., Vikram A., Jesudhasan P., Jayaprakasha G.K, et al. Grapefruit juice and its furocoumarins inhibits autoinducer signaling and biofilm formation in bacteria. Int J Food Microbiol. 2008;125(2):204-208. doi:10.1016/j. ijfoodmicro.2008.03.028

[73] Araújo C.C., Leon L.L. Biological activities of Curcuma longa L. Mem Inst Oswaldo Cruz. 2001;96(5):723-728.

[74] Aggarwal B.B., Sundaram C., Malani N., Ichikawa H. Curcumin: the Indian solid gold. In: The molecular targets and therapeutic uses of curcumin in health and disease. Volume 595 of the series Advances in Experimental Medicine and Biology. Springer, USA; 2007. p. 1-75. doi:10.1007/978-0-387-46401-5_1.

[75] Park B.S., Kim J.G., Kim M.R., Lee S.E., Takeoka G.R., Oh K.B, et al. Curcuma longa L. constituents inhibit sortase A and Staphylococcus aureus cell adhesion to fibronectin. J Agric Food Chem. 2005;53(23):9005-9009. doi:10.1021/jf051765z

[76] Hu P., Huang P., Chen M.W. Curcumin reduces Streptococcus mutans biofilm formation by inhibiting sortase A activity. Arch Oral Biol. 2013;58(10):1343-1348. doi:10.1016/j. archoralbio.2013.05.004

[77] Hu P., Huang P., Chen W.M. Curcumin inhibits the Sortase A activity of the Streptococcus mutans UA159. Appl Biochem Biotechnol. 2013;171(2):396-402. doi:10.1007/ s12010-013-0378-9 
[78] Jayaprakasha G.K., Jaganmohan Rao L., Sakariah K.K. Antioxidant activities of curcumin, demethoxycurcumin and bisdemethoxycurcumin. Food Chem. 2006;98(4):720 724. doi:10.1016/j.foodchem.2005.06.037

[79] Kim D.S., Kim J.Y. Total synthesis of Calebin-A, preparation of its analogues, and their neuronal cell protectivity against beta-amyloid insult. Bioorg Med Chem Lett. 2001;11(18):2541-2543. doi:10.1016/S0960-894X(01)00489-9

[80] Packiavathy I.A., Priya S., Pandian S.K., Ravi A.V. Inhibition of biofilm development of uropathogens by curcumin - an anti-quorum sensing agent from Curcuma longa. Food Chem. 2014;148:453-460. doi:10.1016/j.foodchem.2012.08.002

[81] Magesh H., Kumar A., Alam A., Priyam., Sekar U., Sumantran V.N., Vaidyanathan R. Identification of natural compounds which inhibit biofilm formation in clinical isolates of Klebsiella pneumoniae. Indian J Exp Biol. 2013;51(9):764-772.

[82] Lee J.H., Regmi S.C., Kim J.A., Cho M.H., Yun H., Lee C.S, Lee J. Apple flavonoid phloretin inhibits Escherichia coli O157:H7 biofilm formation and ameliorates colon inflammation in rats. Infect Immun. 2011;79(12):4819-4827. doi:10.1128/IAI.05580-11

[83] Packiavathy I.A., Sasikumar P., Pandian S.K., Veera Ravi A. Prevention of quorumsensing-mediated biofilm development and virulence factors production in Vibrio spp. by curcumin. Appl Microbiol Biotechnol. 2013;97(23):10177-10187. doi:10.1007/ s00253-013-4704-5

[84] Rudrappa T., Bais H.P. Curcumin, a known phenolic from Curcuma longa, attenuates the virulence of Pseudomonas aeruginosa PAO1 in whole plant and animal pathogenicity models. J Agric Food Chem. 2008;56(6):1955-1962. doi:10.1021/jf072591j

[85] Qiu J., Feng H., Lu J., Xiang H., Wang D., Dong J., Wang J., Wang X., Liu J., Deng X. Eugenol reduces the expression of virulence-related exoproteins in Staphylococcus aureus. Appl Environ Microbiol. 2010;76(17):5846-5851. doi:10.1128/AEM.00704-10

[86] Yadav M.K., Chae S.W., Im G.J., Chung J.W., Song J.J. Eugenol: a phyto-compound effective against methicillin-resistant and methicillin-sensitive Staphylococcus aureus clinical strain biofilms. PLoS One. 2015;10(3):e0119564. doi:10.1371/journal.pone.0119564

[87] Zhou L., Zheng H., Tang Y., Yu W., Gong Q. Eugenol inhibits quorum sensing at sub-inhibitory concentrations. Biotechnol Lett. 2013;35(4):631-637. doi:10.1007/s10529-012-1126-X

[88] Musthafa K.S., Voravuthikunchai S.P. Anti-virulence potential of eugenyl acetate against pathogenic bacteria of medical importance. Antonie Van Leeuwenhoek. 2015;107(3):703710. doi:10.1007/s10482-014-0364-4

[89] Ahmad A., Viljoen A.M, Chenia H.Y. The impact of plant volatiles on bacterial quorum sensing. Lett Appl Microbiol. 2015;60(1):8-19. doi:10.1111/lam.12343

[90] Packiavathy I., Agilandeswari P., Musthafa K.S., Pandian S.K, Ravi A.V. Antibiofilm and quorum sensing inhibitory potential of Cuminum cyminum and its secondary metabolite methyl eugenol against Gram negative bacterial pathogens. Food Res Int. 2012;45:85-92. doi:10.1016/j.foodres.2011.10.022 
[91] Hemshekhar M., Sebastin Santhosh M., Kemparaju K., Girish K.S. Emerging roles of anacardic acid and its derivatives: a pharmacological overview. Basic Clin Pharmacol Toxicol. 2012;110(2):122-132. doi:10.1111/j.1742-7843.2011.00833.x

[92] Castillo-Juárez I., García-Contreras R., Velázquez-Guadarrama N., Soto-Hernández M., Martínez-Vázquez M. Amphypterygium adstringens anacardic acid mixture inhibits quorum sensing-controlled virulence factors of Chromobacterium violaceum and Pseudomonas aeruginosa. Arch Med Res. 2013;44(7):488-494. doi:10.1016/j. arcmed.2013.10.004

[93] Lee J.H., Kim Y.G., Ryu S.Y., Cho M.H., Lee J. Ginkgolic acids and Ginkgo biloba extract inhibit Escherichia coli O157:H7 and Staphylococcus aureus biofilm formation. Int J Food Microbiol. 2014;174:47-55. doi:10.1016/j.ijfoodmicro.2013.12.030

[94] Kanojia R.M., Murray W., Bernstein J., Fernandez J., Foleno B.D., Krause H, et al. 6-oxa isosteres of anacardic acids as potent inhibitors of bacterial histidine protein kinase (HPK)-mediated two-component regulatory systems. Bioorg Med Chem Lett. 1999;9(20):2947-2952. doi:10.1016/S0960-894X(99)00508-9

[95] Kumar S., Pandey A.K. Chemistry and biological activities of flavonoids: an overview. Sci World J. 2013;2013:162750. doi:10.1155/2013/162750

[96] Lee J.H., Park J.H., Cho M.H., Lee J. Flavone reduces the production of virulence factors, staphyloxanthin and $\alpha$-hemolysin, in Staphylococcus aureus. Curr Microbiol. 2012;65(6):726-732. doi:10.1007/s00284-012-0229-x

[97] Cho H.S., Lee J.H., Cho M.H., Lee J. Red wines and flavonoids diminish Staphylococcus aureus virulence with anti-biofilm and anti-hemolytic activities. Biofouling. 2015;31(1):111. doi:10.1080/08927014.2014.991319

[98] Kang S.S., Kim J.G., Lee T.H., Oh K.B. Flavonols inhibit sortases and sortase-mediated Staphylococcus aureus clumping to fibrinogen. Biol Pharm Bull. 2006;29(8):1751-1755.

[99] Wang J., Zhou X., Liu S., Li G., Zhang B., Deng X, Niu X. Novel inhibitor discovery and the conformational analysis of inhibitors of listeriolysin $\mathrm{O}$ via protein-ligand modeling. Sci Rep. 2015;5:8864. doi:10.1038/srep08864

[100] Vikram A., Jayaprakasha G.K., Jesudhasan P.R., Pillai S.D., Patil BS. Suppression of bacterial cell-cell signalling, biofilm formation and type III secretion system by citrus flavonoids. J Appl Microbiol. 2010;109(2):515-527. doi:10.1111/j.1365-2672.2010.04677.x

[101] Wang W.B., Lai H.C., Hsueh P.R., Chiou R.Y., Lin S.B., Liaw S.J. Inhibition of swarming and virulence factor expression in Proteus mirabilis by resveratrol. J Med Microbiol. 2006;55:1313-1321. doi:10.1099/jmm.0.46661-0

[102] Augustine N., Goel A.K., Sivakumar K.C., Kumar R.A., Thomas S. Resveratrol-a potential inhibitor of biofilm formation in Vibrio cholerae. Phytomedicine. 2014;21(3):286-289. doi:10.1016/j.phymed.2013.09.010

[103] Baur J.A., Sinclair D.A. Therapeutic potential of resveratrol: the in vivo evidence. Nat Rev Drug Discov. 2006;5(6):493-506. doi:10.1038/nrd2060 
[104] Coenye T., Brackman G., Rigole P., De Witte E., Honraet K., Rossel B., Nelis H.J. Eradication of Propionibacterium acnes biofilms by plant extracts and putative identification of icariin, resveratrol and salidroside as active compounds. Phytomedicine. 2012;19(5):409-412. doi:10.1016/j.phymed.2011.10.005

[105] Lee J.H., Kim Y.G., Ryu S.Y., Cho M.H., Lee J. Resveratrol oligomers inhibit biofilm formation of Escherichia coli O157:H7 and Pseudomonas aeruginosa. J Nat Prod. 2014;77(1):168-172. doi:10.1021/np400756g

[106] Lee J.H., Cho H.S., Joo S.W., Chandra Regmi S., Kim J.A., Ryu C.M, et al. Diverse plant extracts and trans-resveratrol inhibit biofilm formation and swarming of Escherichia coli O157:H7. Biofouling. 2013;29(10):1189-1203. doi:10.1080/08927014.2013.832223

[107] Yuk H.J., Ryu H.W., Jeong S.H., Curtis-Long M.J., Kim H.J., Wang Y,et al. Profiling of neuraminidase inhibitory polyphenols from the seeds of Paeonia lactiflora. Food Chem Toxicol. 2013;55:144-149. doi:10.1016/j.fct.2012.12.053

[108] Cho H.S., Lee J.H., Ryu S.Y., Joo S.W., Cho M.H., Lee J. Inhibition of Pseudomonas aeruginosa and Escherichia coli O157:H7 biofilm formation by plant metabolite $\varepsilon$-viniferin. J Agric Food Chem. 2013;61(29):7120-7126. doi:10.1021/jf4009313

[109] Alvarez M.V., Moreira M.R., Ponce A. Antiquorum sensing and antimicrobial activity of natural agents with potential use in food. J Food Saf. 2012;32(3):379-387. doi:10.1111/j.1745-4565.2012.00390.x

[110] Prithiviraj B., Bais H.P., Weir T., Suresh B., Najarro E.H, Dayakar V, et al. Down regulation of virulence factors of Pseudomonas aeruginosa by salicylic acid attenuates its virulence on Arabidopsis thaliana and Caenorhabditis elegans. Infect Immun. 2005;73(9):5319-5328. doi:10.1128/IAI.73.9.5319-5328.2005

[111] Vlot A.C., Dempsey D.A., Klessig D.F. Salicylic Acid, a multifaceted hormone to combat disease. Annu Rev Phytopathol. 2009;47:177-206. doi:10.1146/annurev.phyto.050908. 135202

[112] Bandara M.B., Zhu H., Sankaridurg P.R., Willcox M.D. Salicylic acid reduces the production of several potential virulence factors of Pseudomonas aeruginosa associated with microbial keratitis. Invest Ophthalmol Vis Sci. 2006;47(10):4453-4460. doi:10.1167/ iovs.06-0288

[113] Sendamangalam V., Choi O.K., Kim D., Seo Y. The anti-biofouling effect of polyphenols against Streptococcus mutans. Biofouling. 2011;27(1):13-19. doi:10.1080/08927014.2010. 535897

[114] Morán A., Gutiérrez S., Martínez-Blanco H., Ferrero M.A., Monteagudo-Mera A., Rodríguez-Aparicio L.B. Non-toxic plant metabolites regulate Staphylococcus viability and biofilm formation: a natural therapeutic strategy useful in the treatment and prevention of skin infections. Biofouling. 2014;30(10):1175-1182. doi:10.1080/08927014.201 4.976207 
[115] Benoit S., Maier R.J. Dependence of Helicobacter pylori urease activity on the nickelsequestering ability of the UreE accessory protein. J Bacteriol. 2003;185(16):4787-4795. doi:10.1128/JB.185.16.4787-4795.2003

[116] Liu W.H., Hsu C.C., Yin M.C. In vitro anti-Helicobacter pylori activity of diallyl sulphides and protocatechuic acid. Phytother Res. 2008;22(1):53-57. doi:10.1002/ptr.2259

[117] Ponnusamy K., Paul D., Kweon J.H. Inhibition of quorum sensing mechanism and Aeromonas hydrophila biofilm formation by vanillin. Environ Eng Sci. 2009;26(8):13591363. doi:10.1089/ees.2008.0415

[118] Bhakd S., Tranum-Jensen J. Alpha-toxin of Staphylococcus aureus. Microbiol Rev. 1991;55(4):733-751.

[119] Luís Â., Silva F., Sousa S., Duarte A.P., Domingues F. Antistaphylococcal and biofilm inhibitory activities of gallic, caffeic, and chlorogenic acids. Biofouling. 2014;30(1):6979. doi:10.1080/08927014.2013.845878

[120] Robbins R.J. Phenolic acids in foods: an overview of analytical methodology. J Agric Food Chem. 2003;51(10):2866-2887. doi:10.1021/jf026182t

[121] Sroka Z., Cisowski W. Hydrogen peroxide scavenging, antioxidant and anti-radical activity of some phenolic acids. Food Chem Toxicol. 2003;41(6): 753-758. doi:10.1016/ S0278-6915(02)00329-0

[122] Stalikas C.D. Extraction, separation, and detection methods for phenolic acids and flavonoids. J Sep Sci. 2007;30(18):3268-3295. doi:10.1002/jssc.200700261

[123] Plyuta V., Zaitseva J., Lobakova E., Zagoskina N., Kuznetsov A., Khmel I. Effect of plant phenolic compounds on biofilm formation by Pseudomonas aeruginosa. APMIS. 2013;121(11):1073-1081. doi:10.1111/apm.12083

[124] García-Contreras, R. Is quorum sensing interference a viable alternative to treat Pseudomonas aeruginosa infections? Front Microbiol. 2016;7:1454. doi:10.3389/fmicb.2016.01454

[125] Weigert M., Ross-Gillespie A., Leinweber A., Pessi G., Brown S.P., Kümmerli R. Manipulating virulence factor availability can have complex consequences for infections. Evol Appl. 2016. doi:10.1101/062570 
